\title{
Porcelain veneers: An update
}

\section{Licówki porcelanowe - uaktualnienie wiedzy}

\author{
Omar El-Mowafy ${ }^{1, A, C, D, F}$, Nihal El-Aawar ${ }^{1, B}$, Nora El-Mowafy ${ }^{2, E}$ \\ 1 Faculty of Dentistry, University of Toronto, Canada \\ ${ }^{2}$ Department of Oral Health Sciences, University of British Columbia, Vancouver, Canada \\ A - research concept and design; $\mathrm{B}$ - collection and/or assembly of data; $\mathrm{C}$ - data analysis and interpretation; \\ $D$ - writing the article; $E$ - critical revision of the article; $F$ - final approval of the article
}

Address for correspondence

Omar El-Mowafy

E-mail: Omar.El-Mowafy@dentistry.utoronto.ca

\section{Funding sources}

None declared

\section{Conflict of interest}

None declared

Received on March 8, 2018

Reviewed on April 4, 2018

Accepted on May 4, 2018

\begin{abstract}
New glass-ceramic restorative materials have been developed over the last few years, with enhanced strength characteristics along with desirable optical properties that make them ideal for the fabrication of esthetic crowns and veneers. The purpose of this paper was to provide an overview of the current state of the art of porcelain veneers as a viable option for the esthetic treatment of anterior teeth, and to illustrate the potential of the newly-developed glass-ceramics. Some historical background about the development of the porcelain veneer concept is provided. A list of indications and contraindications for porcelain veneers is followed by their preparation designs, with emphasis on the importance of maintaining the preparation boundaries within the enamel. Impression-taking procedures, provisional restoration fabrication, the choice of porcelain materials and their intaglio surface treatment are all discussed. A case where veneers made with a lithium-disilicate glass-ceramic were used to improve the appearance of maxillary anterior teeth is included. Several studies reporting on the longevity of porcelain veneers up to 12 years are discussed.
\end{abstract}

Key words: glass-ceramic, update, dental porcelain, longevity

Słowa kluczowe: tworzywo szklano-ceramiczne, uaktualnienie wiedzy, ceramika dentystyczna, trwałość

DOI

$10.17219 / \mathrm{dmp} / 90729$

Copyright

○ 2018 by Wroclaw Medical University

and Polish Dental Society

This is an article distributed under the terms of the

Creative Commons Attribution Non-Commercial License

(http://creativecommons.org/licenses/by-nc-nd/4.0/) 
Porcelain veneers are thin-bonded ceramic prosthetics that restore the facial surface and part of the proximal surfaces of anterior teeth that require esthetic treatment. ${ }^{1}$ They typically consist of thin shells of porcelain, the fitted surface of which has been etched with hydrofluoric acid and coated with a silane coupling agent. Using a resinbased cement, the veneer is bonded to enamel that has been prepared with a phosphoric acid etchant. ${ }^{2}$ Due to their high esthetic appeal, as well as their proven biocompatibility and long-term predictability, porcelain veneers have become a reliable restorative procedure for the treatment of teeth in the front area of the mouth. ${ }^{3,4}$

Porcelain veneers were introduced to the profession by John Calamia of New York University, USA, in the early 1980s. ${ }^{5,6}$ Their development was one of several innovations and outcomes that followed the discovery of acidetching and bonding to enamel that was first reported by Michael Buonocore in the 1950s. ${ }^{7}$ Resin composite formulations based on bisphenol A-glycidyl methacrylate (BisGMA) were introduced to the profession by Rafael Bowen in the early 1960 s. $^{8}$ These resulted in composite restorations with superior physical and mechanical properties, leading to enhanced clinical performance. Following the success of these resin-based restorative composites, resin cements based on Bis-GMA resin were introduced to the profession in the late 1970s. This meant that 3 crucial elements for the development of the porcelain veneer technique had been realized: the ability to acid-etch enamel to produce a microscopically rough surface that is receptive to bonding; the ability to acid-etch the fitted surface of a feldspathic porcelain veneer with hydrofluoric acid to create a microscopically rough surface that is also receptive to bonding to the resin; and the availability of a resin cement that can be used for cementing porcelain veneers to enamel. ${ }^{9}$

\section{Indications and contraindications for porcelain veneers}

Porcelain veneers are ideal for the treatment of discolored vital anterior teeth that do not respond well to bleaching. This includes moderate discoloration caused by tetracycline staining, excessive fluoride uptake, aging, and amelogenesis imperfecta. ${ }^{10}$ Enamel hypocalcification and fractures can also be corrected with porcelain veneers. ${ }^{5,6,11}$ They are also useful for closing moderate spacing between anterior teeth and to treat congenital tooth malformation. ${ }^{12}$ When there is a need to lengthen or reshape maxillary anterior teeth, porcelain veneers provide a conservative treatment option. ${ }^{13,14}$

In contrast, endodontically-treated anterior teeth that are structurally compromised are not suitable candidates for porcelain veneers, as they need the bracing provided by full-coverage crowns to maintain their integrity. Heavily-restored teeth with inadequate enamel are not good candidates either, as enamel is the main source of retention for porcelain veneers. Other precluding conditions are dentition lacking posterior support, poor oral hygiene and existing parafunctional activity, such as bruxism. ${ }^{15,16}$ Magne et al. reported that success rates for porcelain veneers drop to $60 \%$ in patients with bruxism activity; however, this percentage was similar to that obtained for metal-ceramic crowns used in the same situation. ${ }^{17}$

\section{Preparation}

Porcelain veneer preparation is characterized by minimal removal of the tooth structure. Ideally, porcelain veneer preparation should be confined to enamel in terms of the periphery and depth. For maxillary anterior teeth, typical preparation involves the whole facial (labial) surface to a depth of approx. $0.3 \mathrm{~mm}$. In some cases, when there is a need to lengthen the teeth or close interproximal spaces, an incisal and/or proximal wrap-around is indicated. However, the key for proper retention of porcelain veneers is to keep the preparation within the enamel structure. This will ensure superior bonding and will allow avoiding the potential for postoperative sensitivity, which may happen if the dentin is involved in the preparation. The finish line of the preparation is typically of the feather-edge type, considering the minimal amount of enamel removed. Gingivally, it terminates at the gingival margin. An incisal overlap is performed only when needed. It can either be extended as a palatal chamfer or merely as a horizontal incisal reduction (a butt joint).

Porcelain veneer preparations have the advantage of being significantly more conservative than full-coverage crowns, and can address some of the limitations of metalceramic full-coverage crowns. ${ }^{18}$ The advantages include superior optical reflectance due to the elimination of the metallic core; the ability to place margins supragingivally; and improved gingival tissue response as compared to that caused by by some elements in base metal alloys. ${ }^{19}$

\section{Impression-taking for porcelain veneers}

A vinyl poly-siloxane-based impression material is typically used in a custom or stock tray for veneer impression preparation. The retraction cord is positioned to expose the finish line. For computer-aided-designed and computer-aided-manufactured (CAD-CAM) veneers, a digital impression is made with an appropriate scanner.

The temporization of tooth preparation for porcelain laminate veneers is advocated in order to maintain the patient's appearance unchanged and for the overall success of the restoration. ${ }^{20}$ However, in some cases, providing provisional restorations may be optional. Since the preparations involve enamel only, the risk of postop- 
erative sensitivity is non-existent, and since contacts between the teeth are not always broken during the preparation, the risk of tooth shifting is remote. However, when a case dictates the use of provisional restorations, these should be made as one piece, with no attempt to separate individual provisional veneers. This ensures better retention by engaging the interproximal areas, and at the same time maintains the strength of the restorations, which are rather thin and delicate. One technique for cementing temporary porcelain veneers involves spot-etching at the center of the facial surface, followed by applying a bonding resin at the etched point only and using a small amount of a resin cement for attachment. The use of ordinary temporary cements, which are naturally opaque, adversely affects the final esthetic outcome of temporary veneers due to their ultra-thin nature, which allows the cement opacity to show through.

\section{Types of porcelain used for porcelain veneer fabrication}

Traditionally, veneers are fabricated using the manual layering technique from feldspathic porcelain. This necessitates the use of refractory dyes to support the condensed layers of the porcelain slurry. ${ }^{11}$ This technique permits the use of layers with multiple levels of opacity, resulting in optimum esthetics. However, the process is technique-sensitive, and manual mixing and layering of the porcelain may result in the incorporation of small voids. ${ }^{21}$ These voids may cause crack lines or even a fracture to occur over time.

Alternatively, pressed porcelain has been used for the fabrication of veneers. ${ }^{22}$ The main advantages of pressed porcelain are that the resulting veneers have a high level of accuracy and minimal internal structural defects. ${ }^{23}$

Recently, CAD-CAM veneers from glass-ceramic blocks have become available, and their utilization is on the rise. While such veneers are significantly stronger than feldspathic porcelain ones, the color of many of the blocks available is of single opacity. ${ }^{24}$ However, multi-

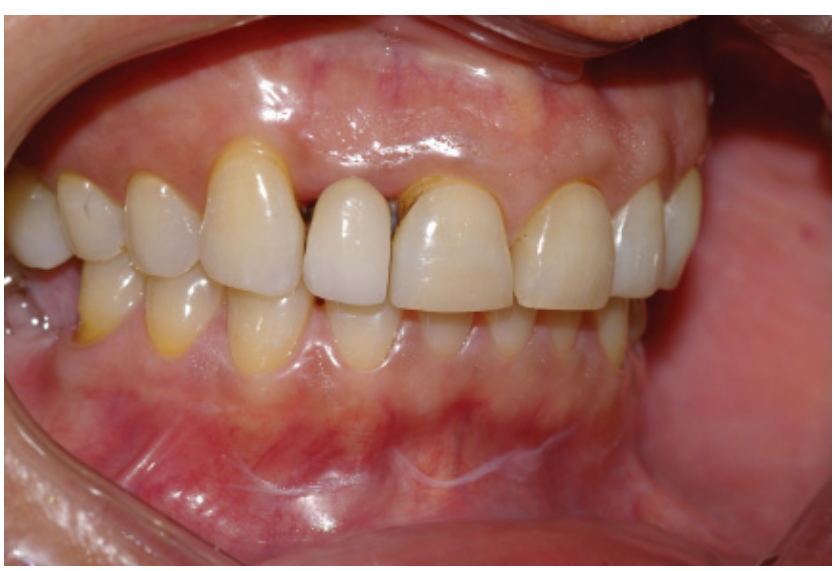

Fig. 1. Maxillary anterior teeth with gingival recession and discoloration opacity blocks are becoming available and can help to overcome this limitation. Figure 1 shows 6 maxillary incisors with discoloration and gingival recession. The right lateral incisor had previously been restored with a ceramo-metal crown. Figure 2 shows a postoperative view with 1 crown and 5 veneers made with milled e.Max $^{\circledR}$ (Ivoclar Vivadent AG, Schaan, Liechtenstein) lithium disilicate glass-ceramic and cemented into place with a resin cement.

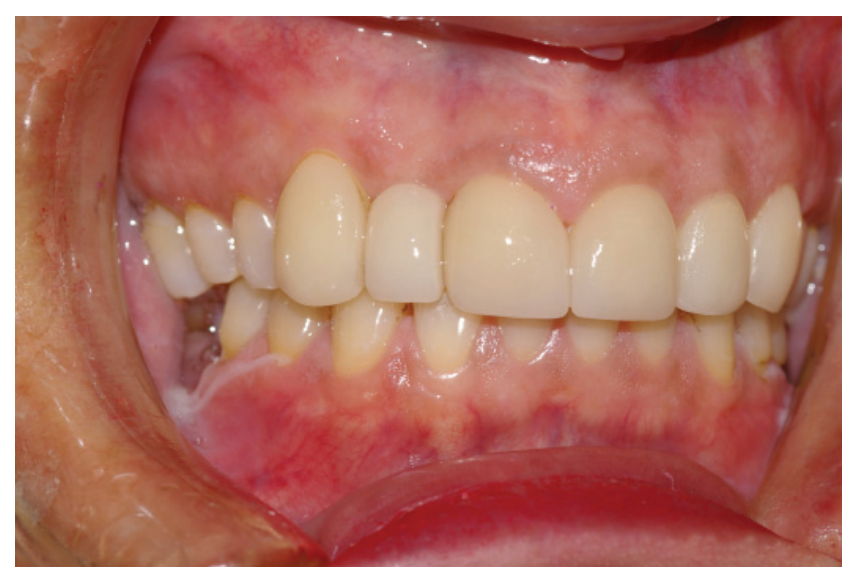

Fig. 2. Five lithium disilicate glass-ceramic e.Max ${ }^{\circledR}$ veneers and 1 crown were made according to a diagnostic mock-up approved by the patient. These were cemented with a light-polymerized resin cement

\section{Surface treatment and cementation}

Acid etching of the fitted surface with hydrofluoric acid has become the standard procedure to render the fitted surface microscopically rough. ${ }^{25-27}$ A silane coupling agent is applied to the etched surface to enhance bonding to the resin cement. ${ }^{28}$ For an optimal ceramic-cement bond, sandblasting the ceramic surfaces with aluminum oxide particles prior to acid-etching with hydrofluoric acid is recommended. ${ }^{29}$

Silane facilitates the adhesion between the inorganic substrate (porcelain) and the organic polymers (resin cement) by increasing porcelain wettability and interlocking. ${ }^{30}$ Moreover, silane is a bifunctional molecule that chemically bonds to the hydrolyzed silicon dioxide of the ceramic surface on one side and to the methacrylate group of the resin cement on the other side. ${ }^{31}$

The attachment of porcelain veneers to the teeth depends on bonding to enamel. An appropriate resin cement is used to achieve this, and to help seal the margins of the veneers, reinforcing the ceramic structure and providing an opportunity to modify the color of the restoration if needed. ${ }^{32,33} \mathrm{~A}$ light-polymerized resin cement is the only type of resin cement that can be used with porcelain veneers. This is because self-polymerized and dual-polymerized resin cements can darken with time, leading to undesirable changes in the color of the veneer. 
As porcelain veneers are very thin, they must be handled carefully during the try-in and subsequent cementation. Excessive finger pressure may cause the veneer to fracture, particularly when a high-viscosity resin cement is used. Low film thickness is desirable for optimum adaptation to the tooth substrate. ${ }^{32,33}$ Seating the restorations with ultrasonic energy has been recommended. ${ }^{34}$ The vibrations, based on the oscillation principles of the ultrasonic device, are helpful in altering the viscosity of the cement, which settles the restoration into place, spreading the luting agent under the restoration and minimizing the potential for future leakage. ${ }^{35-37}$

An important key to success is proper occlusal adjustment after the porcelain veneers are cemented. Occlusion should first be checked in the centric position, and any contacts on the lingual aspects of the newly-cemented veneers must be removed. Similarly, occlusion must be checked in the protrusive mandibular excursion, and any contacts on the lingual aspects of the veneers must be removed. This will ensure that the veneers will be subjected to minimal compressive/shear forces, which is important for their longevity.

\section{Gingival tissue response to porcelain veneers}

Porcelain veneers are typically associated with favorable gingival tissue response due to the location of their gingival margin, which is typically at the gumline or slightly supragingival to the tissues. A proper emergence profile contributes to lowering the incidence of plaque retention, thus helping in the maintenance of periodontal health. ${ }^{38}$ The periodontal response to porcelain veneers reported in the literature varies from clinically acceptable to excellent. ${ }^{39}$

\section{Longevity of porcelain veneers}

The long-term success of porcelain veneers depends on careful case selection, the design of tooth preparation, the material, the laboratory fabrication, and the insertion procedure. Several studies reporting on the longevity of porcelain veneers have been published. Fradeani et al. stated that feldspathic porcelain and glass-infiltrated ceramic veneers presented survival rates ranging from 96\% to $98 \%$ at a 5 -year evaluation. ${ }^{40}$ Similarly, Della Bona and Kelly reported overall failure rates for ceramic veneers of less than $5 \%$ at 5 years. ${ }^{41}$

D'Arcangelo et al. reported that 119 porcelain veneers had a survival rate of $97.5 \%$ at a 7 -year evaluation. ${ }^{42}$ In a retrospective study by Gurel et al., evaluating 580 porcelain veneers with various preparation designs for a 12 -year period, an overall survival rate of $86 \%$ was observed. ${ }^{43}$ The most frequently observed type of failure was a veneer fracture. Preparations with margins on dentin were 10 times more likely to lead to failure than those with margins on enamel.
Beier et al. stated that porcelain veneers offer predictable and successful restoration with an estimated survival rate of more than 10 years. ${ }^{44}$ Layton and Walton reported the longevity of feldspathic porcelain veneers as up to 12 years; at 5 years, the survival rate was $96 \%$, dropping to $93 \%$ at 10 years and to $91 \%$ at 12 years. ${ }^{45}$ A cumulative success rate of approx. 93\% was reported after a 15 -year retrospective clinical observation. ${ }^{46}$ In a 10 -year prospective clinical trial that involved 87 porcelain veneers, none of the veneers were lost. At 5 years, $92 \%$ remained in use without the need for clinical intervention; however, at 10 years, the percentage dropped to $64 \%{ }^{47}$ Large marginal defects were the main failure mode (20\%), particularly when the veneer ended on an existing composite restoration; a porcelain fracture (11\%) was the next most frequent failure. Only $4 \%$ of the veneers needed to be replaced at the 10-year mark.

In a recent systematic review by Morimoto et al., 899 studies were identified, but only 13 were analyzed. ${ }^{48}$ An overall survival rate of $89 \%$ at 9 years was reported; the survival of glass-ceramic veneers (94\%) was higher than that of feldspathic porcelain veneers (87\%). Failure modes included debonding (2\%), a fracture $(4 \%)$, caries $(1 \%)$, and discoloration (2\%). Figure 3 shows a case of a fractured porcelain veneer on a canine.

Calamia and Calamia enumerated keys to success for porcelain veneers that may lead to their survival for up to 25 years. ${ }^{49}$ These included proper treatment planning, preparations terminating in enamel, proper selection of the ceramic to be used, and proper cementation.

In conclusion, porcelain veneers have been used in the profession for more than 30 years. They are characterized by a conservative preparation design with minimal enamel reduction. Proper case selection is key for their success. Several studies have indicated a high survival rate over the long term. When failure occurs, it frequently involves a veneer fracture. The introduction of milled glass-ceramic materials is expected to overcome the fracture issue due to the enhanced strength of this material as compared to the original feldspathic formulations.

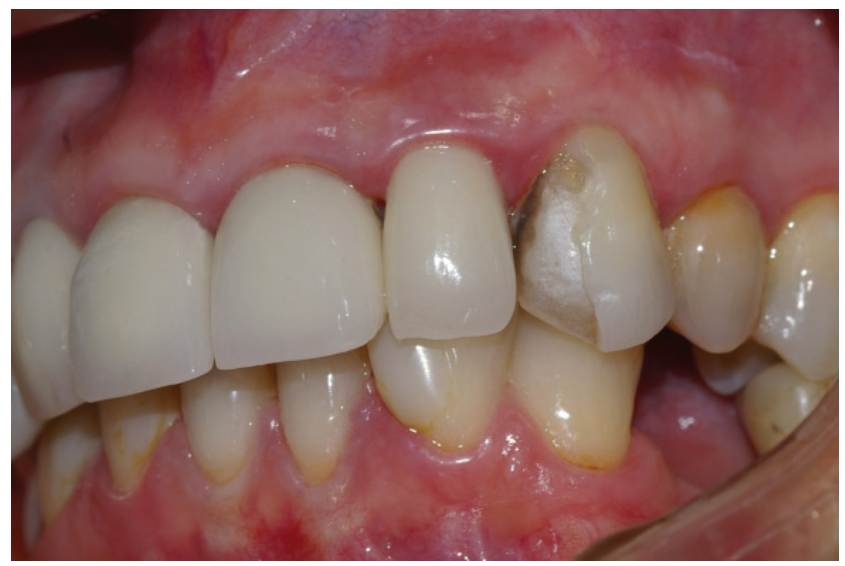

Fig. 3. Maxillary left canine with a vertical fracture of a feldspathic porcelain veneer that took place several years after cementation 


\section{References}

1. The glossary of prosthodontics. J Prosthet Dent. 2017;117:E70.

2. Burke FJ. Survival rate for porcelain laminate veneers with special references to the effect of preparation in dentin: A literature review. J Esthet Restor Dent. 2012;24:257-265.

3. Aykor A, Ozel E. Five-year clinical evaluation of 300 teeth restored with porcelain laminate veneers using total-etch and a modified self-etch adhesive system. Oper Dent. 2009;34:516-523.

4. Goldstein RE. Esthetics in Dentistry. Vol. 1. Principles, Communications, Treatment Methods. $2^{\text {nd }}$ ed. Hamilton, Canada: BC Decker Inc. 1998:14.

5. Calamia JR. Etched porcelain facial veneers: A new treatment modality based on scientific and clinical evidence. NY J Dent. 1983:53:255-259.

6. Calamia JR. Etched porcelain veneers: The current state of the art. Quintessence Int. 1985;16:5-12.

7. Buonocore MG. A simple method of increasing the adhesion of acrylic filling materials to enamel surfaces. J Dent Res. 1955;34:849-853.

8. Bowen RL. Properties of a silica-reinforced polymer for dental restoration. J Am Dent Assoc. 1963;66:57-64.

9. Addison O, Marquis PM, Fleming GJ. Adhesive luting of all-ceramic restorations: The impact of cementation variables and short-term water storage on the strength of a feldspathic dental ceramic. J Adhes Dent. 2008;10:285-293.

10. Jankar AS, Kale Y, Kangane S, Ambekar A, Sinha M, Chaware S. Comparative evaluation of fracture resistance of ceramic veneer with three different incisal design preparations: An in vitro study. J Int Oral Health. 2014;6:48-54.

11. Horn HR. Porcelain laminate veneer bonded to etched enamel: A review. Dent Clin North Am. 1983;27:671-684.

12. Strassler HE. Minimally invasive porcelain veneer: Indications for a conservative esthetic dentistry treatment modality. Gen Dent. 2007;55:686-712.

13. Cehreli MC, Iplikçioglu H. Five-year follow-up of InCeram laminate restorations: A clinical report. J Prosthet Dent. 2000;84:487-489.

14. Freire A, Archegas LR. Porcelain laminate veneer on a highly discolored tooth: A case report. J Can Dent Assoc. 2010;76:a126.

15. Walls AWG. The use of adhesively retained all-porcelain veneers during the management of fractured and worn anterior teeth. Part 2. Clinical result after five-years follow-up. Br Dent J. 1995;178:337-340.

16. Peumans $M$, Van Meerbeeck B, Yoshida $Y$, Lambrechts $P$, Vanherle G. Five-year clinical performance of porcelain veneers. Quintes sence Int. 1998;29:211-221.

17. Magne P, Perroud R, Hodges JS, Belser UC. Clinical performance of novel-design porcelain veneers for the recovery of coronal volume and length. Int J Periodontics Restorative Dent. 2000;20:440-457.

18. Chen W, Raigrodski AJ. A conservative approach for treating young adult patients with porcelain laminate veneers. J Esthet Restor Dent. 2008;20:223-238.

19. Pippin DJ, Mixson JM, Soldan-Els AP. Clinical evaluation of restored maxillary incisors: Veneers vs PFM crowns. J Am Dent Assoc. 1995;126:1523-1529.

20. Kumar Vinod G, Soorya Poduval T, Reddy B, Shesha Reddy P. A study on provisional cements, cementation techniques, and their effects on bonding of porcelain laminate veneers. J Indian Prosthodont Soc. 2014;14:42-49.

21. Taskonak B, Anusavice K, Mecholsky J. Role of investment interaction layer on strength and toughness of ceramic laminates. Dent Mater. 2004;20:701-708

22. Shuman IE. Esthetic treatment with a pressed ceramic veneer material: Case reports. Dent Today. 2004;23:80-84.

23. Mormann WH. The evolution of CEREC system. J Am Dent Assoc. 2006;137(Suppl):7S-13S.

24. Vafiadis D, Goldstein G. Single visit fabrication of a porcelain laminate veneer with CAD/CAM technology: A clinical report. J Prosthet Dent. 2011;106:71-74.

25. Stangel I, Nathanson D, Hsu CS. Shear strength of the composite bond to etched porcelain. J Dent Res. 1987;66:1460-1465.

26. Kursoglu P, Motro PFK, Yurdaguven $\mathrm{H}$. Shear bond strength of resin cement to an acid etched and a laser irradiated ceramic surface. J Adv Prosthodont. 2013:5:98-103.
27. Valian A, Moravej-Salehi E. Surface treatment of feldspathic porcelain: Scanning electron microscopy analysis. J Adv Prosthodont. 2014;6:387-394.

28. Aida M, Hayakawa T, Mizukawa K. Adhesion of composite to porcelain with various surface conditions. J Prosthet Dent. 1995;73:464-470.

29. Kato $H$, Matsumura $H$, Tanaka T, Atsuta M. Bond strength and durability of porcelain bonding systems. J Prosthet Dent. 1996;75:163-168.

30. Blatz MB, Sadan A, Kern M. Resin-ceramic bonding: A review of the literature. J Prosthet Dent. 2003;89:268-274.

31. Meshramkar R, Sajjan S. A comparative evaluation of shear bond strength of porcelain and composite using different bonding agents: An in vitro study. J Indian Prosthodont Soc. 2010;10(1):36-40.

32. Rosentritt M, Behr M, Kolbeck C, Handel G. Marginal integrity of CAD/CAM fixed partial dentures. Eur J Dent. 2007;1:25-30.

33. Touati $B$, Miara P. Light transmission in bonded ceramic restorations. J Esthet Dent. 1993;5:11-18.

34. Cantoro A, Goracci C, Coniglio I, Magni E, Polimeni A, Ferrari M. Influence of ultra-sound application on inlay luting with self-adhesive resin cements. Clin Oral Investig. 2011;15:617-623.

35. Judge RB, Wilson PR. The effect of oscillating forces upon the flow of dental cements. J Oral Rehabil. 1999;26:892-899.

36. Schmidlin PR, Zehnder M, Schup-Mityko C, Gohring TN. Interface evaluation after manual and ultrasonic insertion of standardized class I inlays using composite resin materials of different viscosity. Acta Odontol Scand. 2005;63:205-212.

37. Peutzfelt A. Effect of the ultrasonic insertion technique on the seating of composite inlays. Acta Odontol Scand. 1994;52:51-54.

38. Reeves WG. Restorative margin placement and periodontal health. J Prosthet Dent. 1991;66:7333-7336.

39. Shuman IE. Esthetic treatment with a pressed ceramic veneer material: Case reports. Dent Today. 2004;23:80-84.

40. Fradeani $M$, Redemagni M, Corrado M. Porcelain laminate veneers: 6- to 12-year clinical evaluation. A retrospective study. Int J Periodontics Restorative Dent. 2005;25:9-17.

41. Della Bona A, Kelly JR. The clinical success of all-ceramic restorations. J Am Dent Assoc. 2008;139(Suppl):8-13.

42. D'Arcangelo $C$, De Angelis F, Vadini M, D'Amario M. Clinical evaluation on porcelain laminate veneers bonded with light-cured composite: Results up to 7 years. Clin Oral Investig. 2012;16:1071-1079.

43. Gurel G, Sesma N, Calamita MA, et al. Influence of enamel preservation on failure rates of porcelain laminate veneers. Int $J$ Periodontics Restorative Dent. 2013;33:31-39.

44. Beier US, Kapferer I, Burtscher D, Dumfahrt H. Clinical performance of porcelain laminate veneers for up to 20 years. Int J Prosthodont. 2012;25:79-85.

45. Layton D, Walton T. An up to 16-year prospective study of 304 porcelain veneers. Int J Prosthodont. 2007;20:389-396.

46. Friedman MJ. A 15-year review of porcelain veneer failure: A clinician's observations. Compend Contin Educ Dent. 1998;19:625-636.

47. Peumans $M$, De Munck J, Fieuws S, Lambrechts P, Vanherle G, Van Meerbeek B. A prospective ten-year clinical trial of porcelain veneers. J Adhes Dent. 2004;6:65-76.

48. Morimoto S, Albanesi RB, Sesma N, Agra CM, Braga MM. Main clinical outcomes of feldspathic porcelain and glass-ceramic laminate veneers: A systematic review and meta-analysis of survival complication rates. Int J Prosth. 2016;29:38-47.

49. Calamia JR, Calamia CS. Porcelain laminate veneers: Reasons for 25 years of success. Dent Clin North Am. 2007;51:399-417. 
